\title{
重力波検出干渉計用大口径ミラーの評価
}

\author{
上田 暁俊, 植田 憲一, 佐藤 修一*, 三代木 伸二*, , 大橋 正健 ${ }^{*}$, 伊藤 和彦 $* *$ \\ 渡邊 晃司**, 中村憲司 $* *$, 北島 直哉 $* *$, 潟岡 泉** \\ 電気通信大学レーザー極限技術研究センター（† 182-8585 東京都調布市調布ヶ丘 1-5-1） \\ *国立天文台 宇宙計量部門（广 181-8588 東京都三鷹市大沢 2-21-2） \\ **日本航空電子工業 (株) 中央研究所（１ 196-0021 東京都昭島市武蔵野 3-1-1）
}

\section{Measurement of Optical Characteristics for Mirrors of the Gravitational Wave Detection Antenna}

\author{
Akitoshi UEDA, Ken-ichi UEDA, Shuichi SATO,* Shinji MIYOKI,,${ }^{\dagger}$ Masatake OHASHI* \\ Kazuhiko ITOU,** Koji WATANABE,** Kenji NAKAMURA** \\ Naoya KITAJIMA,** and Izumi KATAOKA** \\ Institute for Laser Science, the University of Electro-Communications, 1-5-1 Choufugaoka, Choufu, Tokyo 182-8585 \\ * National Astronomy Observatory at Mitaka, 2-21-1 Osawa, Mitaka, Tokyo 181-8588 \\ **Central Research Laboratory, Japan Aviation Electronics Industry Ltd. \\ 3-1-1 Musashino, Akishima, Tokyo 196-0021
}

(Received August 18, 1998)

\begin{abstract}
We measured the optical characteristics of ultra low-loss and high reflectance mirrors. Reflectance was evaluated by means of finesse measurement using the ring down method. The mirrors show a loss of $4.8 \mathrm{ppm}$ and finesse of nearly equal to $10^{5}$. Surface distribution of reflectance was measured for ultra-high quality mirrors fabricated with a RF-type Ion Beam Sputtering machine. The average reflectance was $99.9915 \%$ with a standard deviation of $8 \mathrm{ppm}$. The measured area was $5 \times 5 \mathrm{~mm}$ by step of $0.5 \mathrm{~mm}$. Two-dimensional mapping of mirror loss was measured for the mirrors of a $20 \mathrm{~m}$ gravitational wave detection antenna using small laser spot. The mirror loss coefficient was evaluated based on the transmission efficiency of the Fabry-Pérot cavity. The measured area was $7.5 \times 5 \mathrm{~mm}$. The average loss value was $40 \mathrm{ppm}$ for the small laser spot measurement. The mirror loss coefficient for a large beam was measured using a $20 \mathrm{~m}$ Fabry-Pérot cavity. The mirrors show a loss of 28 ppm and a reflectance of $99.9875 \%$.
\end{abstract}

Key Words: Gravitational wave detector, Fabry-Pérot cavity, High-quality mirror

\section{1.はじめに}

我々のグループでは,重力波干渉計用超高品質ミラーの開 発を行ってきた。重力波が伝播してきた場合, 空間に $\Delta L / L=$ $10^{-21}$ 程度の歪みが生じ, この歪みをマイケルソン型干渉計 で検出する。この干渉計は, 実効的な干渋計距離老稼ぐた めに, それぞれの腕がFabry-Pérot干渉計で構成されてい る. 到達重力波の予想周波数は $1 \mathrm{kHz}$ 以下であり,この領域 で干渉計および光源は超高安定化されている必要があ る。レーザーは $10^{-6} \mathrm{~Hz} / \sqrt{\mathrm{Hz}}$ の周波数安定度を必要として いる。この安定度を得るために,レーザーを, Pound-DreverHall法で基準共振器に安定化し ${ }^{1}$, 基準共振器の透過光を干 涉計光源として使用する。したがって, 基準共振器は高反
射率, 高透過効率の必要がある．現在, 国立天文台の敷地内 に, 300mの重力波干渉計が建設されている(TAMA-300). ここで使用するミラーも同様に超低損失, 高反射率の必要 がある。ミラーの性能を高感度に評価するためには二枚 のミラーを使用し, Fabry-Pérot共振器を作製し, そのフィネ スと透過効率を求める。この場合得られる, 共振器線幅は $\mathrm{kHz}$ 程度であり, 高精度にミラーの性能を決めるには, 十分 に安定化された光源が必要となる。したがって, 重力波干渉 計用超高安定化レーザーを開発すると同時に, ミラー評価 技術の開発を行ってきた。ミラー反射率の評価方法とし て,AM-sideband法, 伝達関数測定法 ${ }^{2}$, 共振器光子寿命測定 法3)の3種類を開発し, 周波数領域および時間領域でのフィ ネス評価が可能となっている．現在, 我々のグループでは

\footnotetext{
†現在の所属：東京大学 宇宙線研究所（广 188-8502 東京都田無市緑町 3-2-1）

$\dagger$ †resent address: Institute for Cosmic Ray Research (ICRR), Tokyo University, 3-2-1 Midoricho, Tanashi, Tokyo 188-8502
} 
Kaufman型イオンビームスパッタリング(IBS) 装置を用い て損失 $1.5 \mathrm{ppm}$ の超高品質ミラーを得ることに成功してい る4).しかし, Kaufman型IBSには, フィラメントからの不 純物放出や, 成膜中のフィラメント切断などの問題が有り, 超高品質光学薄膜の作製は, 徐々にRF型IBSに移行しつつ ある、RF型IBSはイオンガンより不純物が発生する確率が 低く, 生成するプラズマ密度が高く, 大きな出力のイオン ビームが得られる。 また, イオンガン内にてラジカルな酸 素を生成することが可能であり, これらは, 大口径超高品 質薄膜の作成に有利であると考えられる。したがって, 新 たに導入した, RF型IBSの条件出しを行い, 重力波干渉計 TAMA-300に使用する直径 $100 \mathrm{~mm}$ のミラーの成膜を行う事 になった。この装置での条件設定が終了し, 超高品質光学 素子の作成が可能となった。本稿では, RF型IBS装置によ り成膜した超高性能ミラーの評価結果および重力波干渉 計用ミラーの最終仕様について報告する。

\section{2. 実 験}

\section{1 ミラーの損失評価}

Fig.1に実験配置図を示す。フィネスの計測は共振器内 光子寿命法により行った. 光源はNd:YAGレーザー (Lightwave: 124-1064-010-F), 発振波長は1064nmである。音響光 学素子 $(\mathrm{AOM})$ の1次回折光を共振器に入射している. 共振

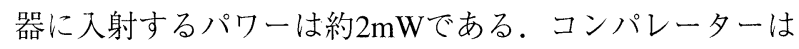
共振器からの反射パワーと参照電圧を比較し, 反射パワー が参照電圧よりも低くなったときにコンパレーターが動 作し, AOMが共振器入力を遮断する. 共振器反射率が減少 するということは, 入射光が光共振器にモード整合して, 入 力パワーが共振器に蓄積された結果である。この時の共 振器出射光の減衰信号をデジタルオシロスコープ(Hewlett Packard: HP-54600A) で観測する．光入力が遮断された条 件での出力信号は, 共振器内の光強度の減衰時定数, すな わち共振器内光子寿命を示す. 光強度減衰定数を $\tau_{c}$, 共振 器長を $L$ とた場合, 反射率 $R$ と減衰定数の関係は

$$
R=1-\frac{L}{c \tau_{c}}
$$

で与えられる。ここで, $c$ は光速である．共振器の透過効率

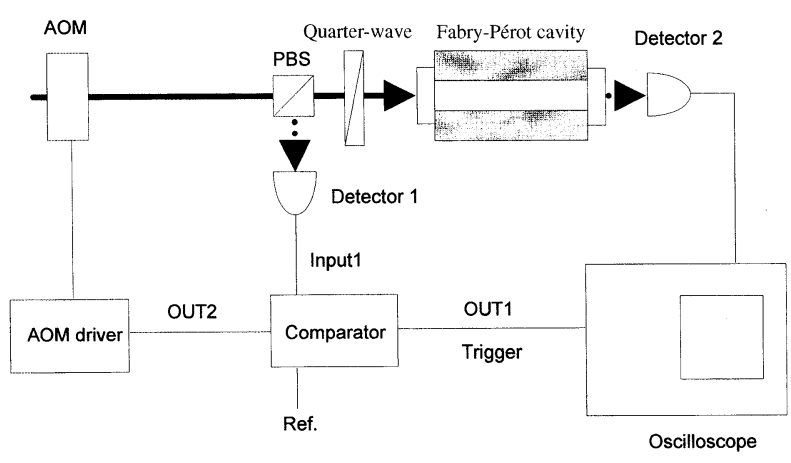

Fig.1 Experimental setup for measuring cavity finesse. Laser emission wavelength is $1064 \mathrm{~nm}$, its optical power is about $16 \mathrm{~mW}$. The cavity length is $200 \mathrm{~mm}$.
は, 共振器に入射している光パワー $P_{i n}$ 共振器を透過する光 パワー $P_{\text {out }}$, ミラー透過効率 $T$ および損失 $A$ を用いて

$$
\eta_{t}=\frac{P_{o u t}}{P_{\text {in }}}=\frac{T^{2}}{(A+T)^{2}}
$$

で与えられる。この式とエネルギー保存則 $R+T+A=1$ よ $\eta$, 反射率及び共振器透過効率の計測を行えば, 反射率, 透 過効率, 損失を得ることができる。今回測定に使用したミ ラーは, $\mathrm{Ta}_{2} \mathrm{O}_{5} / \mathrm{SiO}_{2} 32$ 層からなる誘電体多層膜ミラーであ り, RF型IBS装置で成膜された，測定に用いたFabry-Pérot 共振器は, 平面と曲率 $1000 \mathrm{~mm}$ のミラーで構成され, 共振器 長は200mmである。非同時成膜の2組のミラーについて評 価を行った結果をFig.2に示す。灰色線は10回の計測結果 を別々にプロットしたものであり, 黒線はその平均值を示 している. 曲線 (a)で表されるミラーの共振器光子寿命は $20.19 \mu \mathrm{s}$ であり, 共振線幅は7.9kHz, フィネスは95171であっ た。この結果より反射率は $99.9967 \%$ と求まった。共振器

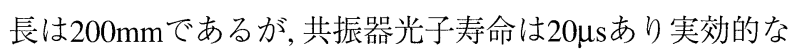

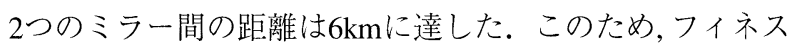
を測定するためには非常に高いアライメント精度が必要 で, 同時に, 共振器自身が十分に安定でなくてはならない. 加えて, 共振線幅は $8 \mathrm{kHz}$ 程度であり,この值は通常のレー ザーの線幅が100MHz程度であるのに比べて非常に狭い。 したがって, ミラー評価を高精度に行うためには,十分に 周波数安定化した光源が必要となる. 共振器の透過効率 は72.8\%であり,これらの結果より損失は $4.8 \mathrm{ppm}$, 透過は 28.2ppmとなった. 他方の試作ミラーについての計測結果 はFig.2の (b)であらわされる曲線となり, 共振器光子寿命

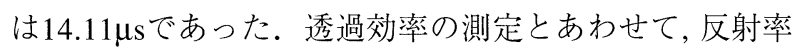
99.9953\%, 損失 $5.8 \mathrm{ppm}$, 透過 $41.4 \mathrm{ppm}$ という結果を得た. 反 射率は試料間で若干異なっているが, 損失についてはほぼ 同じ值となっており, 定常的にこのような超低損失ミラー

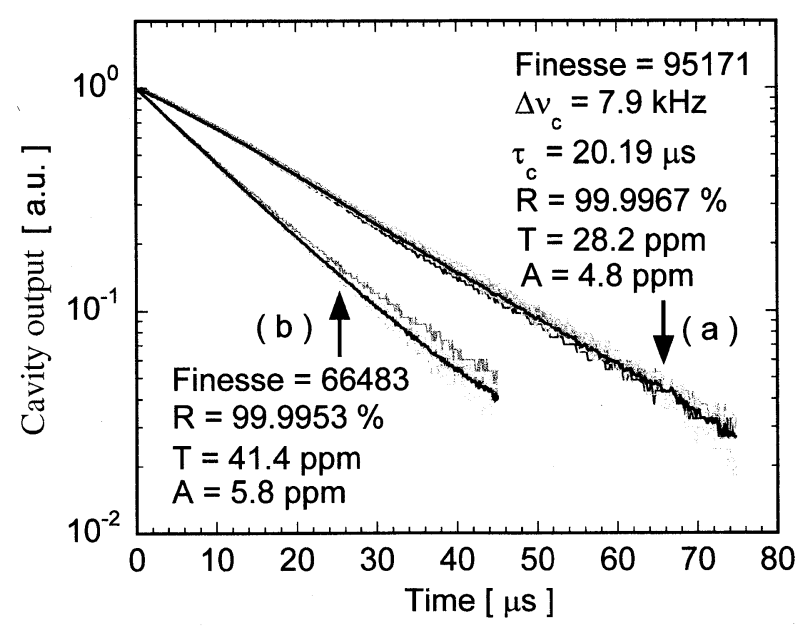

Fig.2 Measurement of cavity decay time constant using the ring-down method. The gray lines show 10 times measurements of cavity decay time constant. The solid lines are average of the ten times measurements for each Fabry-Pérot cavities. The data shows that the cavity has finesse of nearly equal to $10^{5}$. The two sets of mirrors is fabricated in different running time of the IBS machine. 
をRF-IBS装置で作成することが可能である：二組のミ ラーの反射率差はわずかに $1.4 \times 10^{-3} \% て ゙ あ り ，$ 通常の測定 では区別することが困難である。しかし，その共振器光子 寿命は大きく異なっており 99.999\%近い反射率を非常に高 い精度で決めることが可能となる。これらのミラーの評 価結果と誤差を, Table 1に示す。誤差は, 10回の測定の分 散值である。これまで, RF型IBS装置ではビームの均一性 や膜内欠陥の問題があり, 高品質な光学薄膜を作成するこ とが出来なかったが, 成膜条件の最適化により, Kaufman型 IBS装置に匹敵するような, 超高品質光学薄膜の作製が可 能となった. Kaufman型IBS装置では, フィラメントからの 初期放出物質による污染や, 有限のフィラメント寿命など, 最良の成膜が可能な期間が限られていた。 また, 大口径イ オンガンの動作にも問題があった。そこで, RF型IBS装置 の導入により大口径超高品質光学薄膜の試作を行い, その 光学特性を測定した。

\section{2 ミラー性能の二次元評価}

これまでの計測では, 共振器長 $200 \mathrm{~mm}$ 程度の小型干渉計 を用いてミラーの性能評価を行ってきた。この場合, 共振 器モードに整合するビームサイズは $0.4 \mathrm{~mm}$ 程度であった。

しかし,TAMA-300のような大規模干渉計では, ミラー性能 の不均一性や理想球面がらのずれにより, ビーム内の位相 の乱れ等が発生すると,それらは新たに損失の要因として 加わり, 小型干渉計で得られた性能とは異なる值を示す可 能性がある．大規模干渉計を稼動しミラーの性能を評価 することは容易でないので, 小型干渉計において光学パラ メータの二次元分布を測定することにした。これにより， 実際の使用状況における性能についても, ある程度予測可 能である. 従来, ミラーの光学パラメータ計測は, スーパー インバーなどの中空ロッドの両端にミラーを固定し, 安定 な共振器を構成することで行ってきた. しかし, 二次元の ミラー性能を測定するためには, 共振器を構成するミラー をそれぞれ独立なミラーホルダーに入れ, 光軸と垂直な平 面内でミラーを可動とする必要がある. 測定対象となっ ているミラーは反射率 $99.99 \%$ 程度であり,二つのミラー間 の実効的な距離は $\mathrm{km}$ となる。したがって, 地面振動による ミラーアライメントの微小変化が測定に大きな影響を与 える。この共振器構成に対し, Pound-Drever-Hall法でレー ザーを安定化しその周波数安定度を測定した場合, フーリ 工周波数で $200 \mathrm{~Hz}$ 以下の領域の安定度が, 共振器を中空 ロッドで構成した場合に比べ3桁以上悪化する。しかし, 高

Table 1 Measured optical characteristics of the F-P cavity.

\begin{tabular}{cc}
\hline \hline$L$ & $200.0 \pm 1.0 \mathrm{~mm}$ \\
$F S R$ & $750.0 \pm 3.8 \mathrm{MHz}$ \\
\hline
\end{tabular}

\begin{tabular}{ccc}
\hline & Mirror set 1 & Mirror set 2 \\
\hline$\tau_{\mathrm{c}}$ & $20.19 \pm 0.61 \mu \mathrm{s}$ & $14.11 \pm 0.41 \mu \mathrm{s}$ \\
$\Delta v_{\mathrm{c}}$ & $7.880 \pm 0.229 \mathrm{kHz}$ & $11.28 \pm 0.320 \mathrm{kHz}$ \\
$F$ & $95171 \mp 3347$ & $66483 \mp 2285$ \\
$R$ & $99.9967 \pm 0.0001 \%$ & $99.9953 \pm 0.0002 \%$ \\
$T$ & $28.2 \pm 0.9 \mathrm{ppm}$ & $41.4 \pm 0.9 \mathrm{ppm}$ \\
$\mathrm{A}$ & $4.8 \pm 0.2 \mathrm{ppm}$ & $5.8 \pm 0.7 \mathrm{ppm}$ \\
\hline \hline
\end{tabular}

周波領域での振動の影響は比較的小さい5)。 もし,フィネ スの測定時間が,外部雑音の周期よりも十分に短ければ, 精 密に反射率を測定することが可能である。これを考慮す ると, 測定時間中にレーザーが共振器モードに結合してい る必要がなく, 短時間で測定の終了する共振器光子寿命測 定法が, 2次元計測にはもっとも適した方法だといえる。こ の共振器構成による共振器光子寿命の測定例を Fig.3に示 す. 得られた信号は単一時定数で減衰しており, 外部雑音 の計測に対する影響は見られない。この共振器構成で, レーザー入射側のミラーを参照ミラーとし, 出射ミラーを 動かすことによりKaufman型IBS装置で作製したミラーに 対し, 反射率面分布の測定を行った。測定ミラーを動かす ことによるモード整合率の低下は10\%以下であり, 参照ミ ラー上でのビームの安定性は十分ある。しかし, 念のため, 1方向に掃引する毎に測定ミラーをアライメントし直し, 参 照ミラー上でのビームの安定性を向上させている. Fig.4

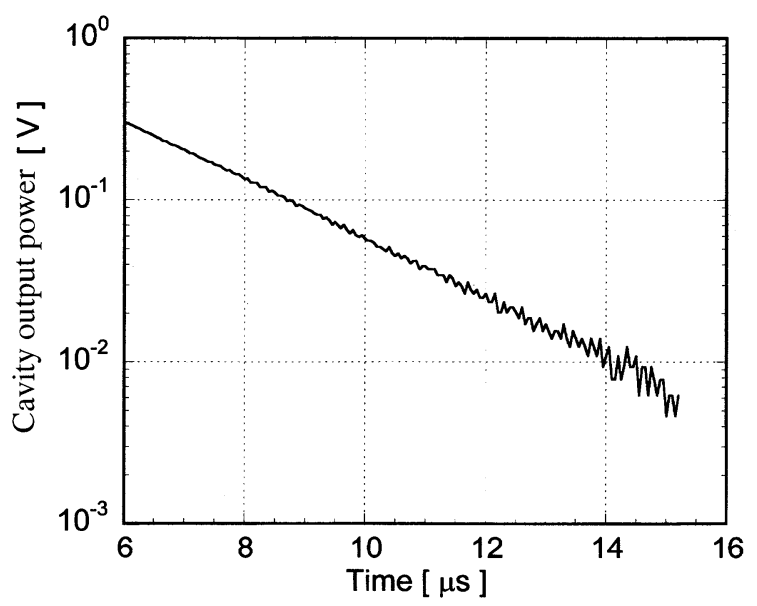

Fig.3 Cavity decay signal. The free standing mirrors compose the Fabry-Pérot cavity. The decay signal has a single decay time coefficient. Influence of external noise is not observed on this measurement.

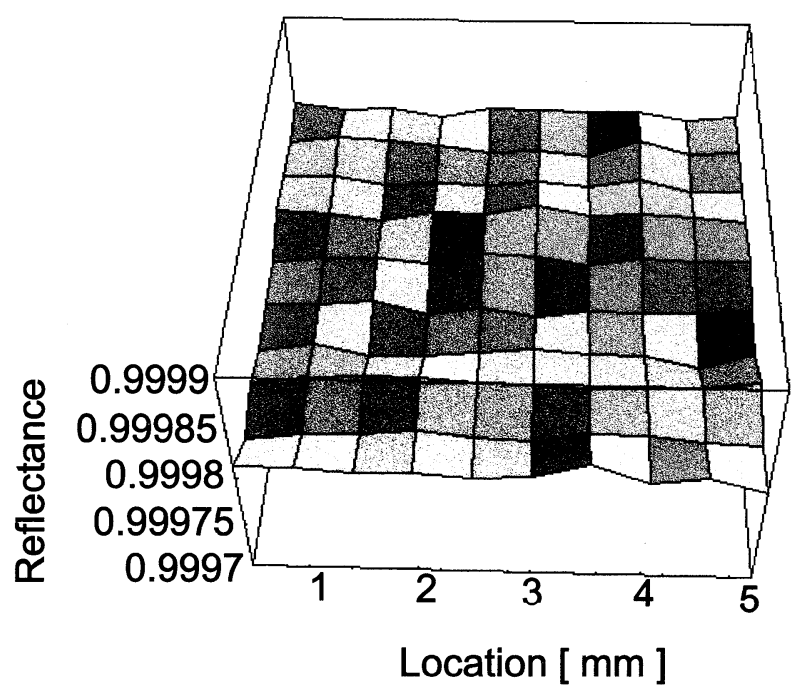

Fig.4 Two-dimensional mapping of reflectance. The mirrors are fabricated with a Kaufman-type IBS machine. Average value of the reflectance is $99.9810 \%$ with standard deviation of $8 \mathrm{ppm}$. Measured area is 5 square $\mathrm{mm}$ by step of $0.5 \mathrm{~mm}$. 
は, Kaufman型IBS装置で作製されたミラーの反射率面分布 を示している。測定領域は $5 \times 5 \mathrm{~mm}$ で $0.5 \mathrm{~mm}$ 毎に反射率測 定を行っている. 反射率の平均值は, $99.9810 \%$, その分散 は8ppmであった．同様の測定をRF型IBS装置で作製した ミラーについて行い, 反射率の平均值 $99.9915 \%$, 分散值 15ppmを得ている. RF-IBS装置で作製した別のミラーにつ いて, 反射率面分布計測と同じように計測を行い, ミラー の損失マッピングを行った. 共振器長は $600 \mathrm{~mm}$ でミラー 上のビーム径は $0.3 \mathrm{~mm}$ であり, 測定領域は $7.5 \mathrm{~mm} \times 5 \mathrm{~mm}$ で, $7.5 \mathrm{~mm}$ 方向は $0.5 \mathrm{~mm}$ 毎, $5 \mathrm{~mm}$ 方向は $1 \mathrm{~mm}$ 毎に計測を行っ た.この測定で得られた損失值のヒストグラムをFig.5に 示す．損失は50ppmまでに大きな分布をもち,それ以上の 部分で損失の大きな特異点がある。 $50 \mathrm{ppm}$ までは, 均質膜 からの損失であり, それ以上は膜欠陷領域からの損失と考 えられる. 特異点を除いた損失の平均值は $27 \mathrm{ppm}$ であっ た. 小口径ビームで損失を測定した場合, ビーム径に対す る欠陥の面積比が大きくなるために特異的な大損失を示 すが, 大口径ビームで損失測定を行った場合にはその比が 非常に小さくなり, 久陉の損失に与える影響は小さくな る.したがって, ビームの位相乱れなどによる大幅な損失 の増加がなければ, 大口径ビームで測定を行った場合の損 失值は, $27 \mathrm{ppm} に$ 近い值となることが期待される. TAMA300のモード径は $15 \mathrm{~mm}$ であり，この測定に用いたビーム面 積の2500倍である。

\section{$2.320 \mathrm{~m}$ 干渉計による損失評価}

現在, 国立天文台ではTAMA-300のプロトタイプである $20 \mathrm{~m}$ 重力波干渉計が稼動している。この干渉計を用いて, 大口径ビームに対するミラー性能の評価を行った．共振 器長は, $1.99 \times 10^{4} \mathrm{~mm}$ あ゙る。共振器は真空中に設置され, 10-7 torrまで減压してある。したがって, 大気の吸収による 損失測定への影響はない。共振器を構成するミラーは, ワ イヤーで吊るすとともに位置制御が加えられ, 防振されて いる. フィネスの測定は, 共振器の伝達関数を測定するこ

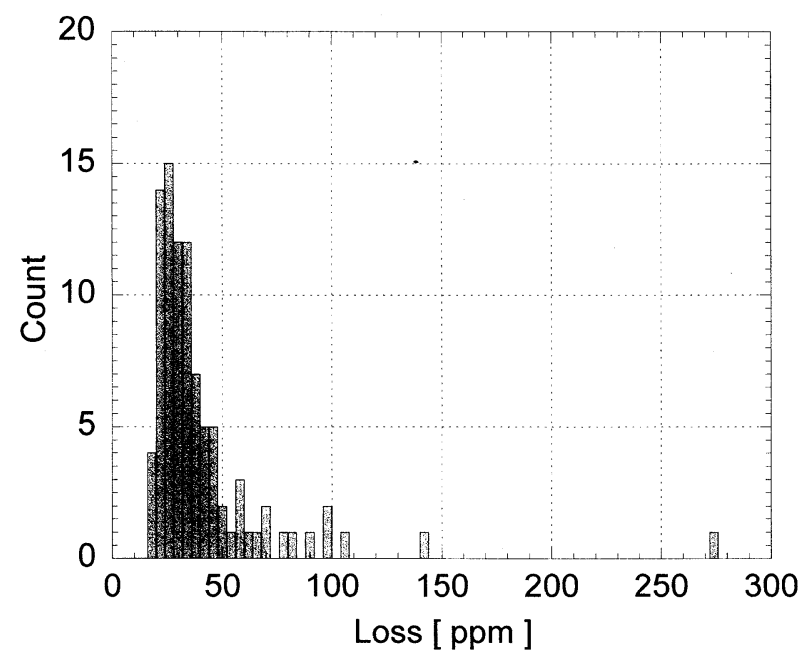

Fig.5 Histogram of measured loss using small beam. The average value of the loss is $40 \mathrm{ppm}$ for the measured region of $7.5 \times 5 \mathrm{~mm}$ and $27 \mathrm{ppm}$ with exception of exceptional large defect points.

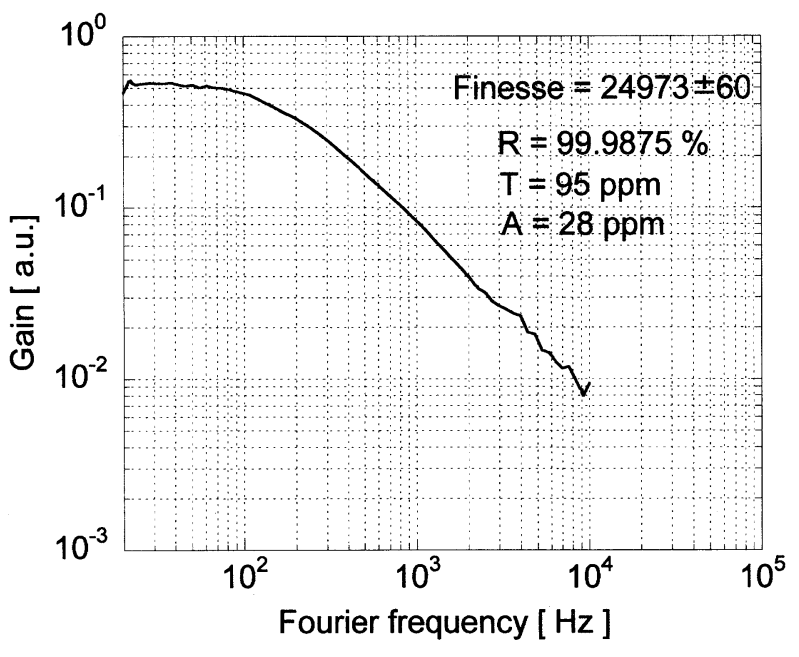

Fig.6 Measurement of frequency response of the FabryPérot cavity. The cavity length is $1.99 \times 10^{4} \mathrm{~mm}$. The Fabry-Pérot mirrors are locked to the laser using the Pound-Drever-Hall technique. Measured finesse value is 24973 .

とにより行った。伝達関数は, Pound-Drever-Hall法で入射 光に対し共振器を安定化し, 入射光に掃引サイン波でAM 変調を掛け, その時の共振器透過光を測定することにより 求めた. この時, 共振器の伝達関数は, 共振器の透過曲線 の半值半幅を $f_{c}$ とし

$$
|H(f)|=\frac{1}{\sqrt{1+\left(\frac{f}{f_{c}}\right)^{2}}}
$$

で与えられる2)。ここで,fはフーリエ周波数である．Fig.6 に測定波形を示す。データーは一回の計測によるもので, 測定誤差は最小二乗法によるフィッティング誤差であ る。この計測によりフィネスは24973と求まり, 反射率は 99.9875\%となった。また, 透過効率の計測より, 損失は $28 \mathrm{ppm}$ となった。ビーム径は8 $\mathrm{mm}$ であり, 測定值はこの領 域での平均值を示している。損失面分布の測定において, 大損失部分を除いた平均值は $27 \mathrm{ppm}$ であり, 小口径ビーム による計測と非常に近く, 大口径化によって生じるである うと考えていた位相乱れ等による損失の増加は, 認められ なかった，損失面分布の測定において, 測定ビーム径は, ミ ラーの位置移動距離に比べて小さく, 未測定部分が測定領 域内に存在する, しかし大口径ビームでの計測結果より,こ の領域に膜欠陥が点在している可能性はない.したがっ て, 膜の欠陥発生確率は非常に小さく, $20 \mathrm{~m}$ 干渉計よりも更 に大きな口径を必要とするTAMA-300のミラーにおいて も, 十分に超高品質成膜が可能であると判断し, 重力波干 渉計用ミラーの成膜最終仕様を決定するとともに最終成 膜に着手した。TAMA-300用ミラーの最終仕様は, 成膜径 $100 \mathrm{~mm}$, 成膜層数, $\mathrm{Ta}_{2} \mathrm{O}_{5} / \mathrm{SiO}_{2} 30$ 層, 反射率 $99.99 \%$ 以上, 反 射率面分布 $10 \mathrm{ppm}$ 以下, 損失は実際の使用状況において 50ppm以下である。 


\section{3. 結果及び考察}

ミラーの面性能を均一にするためには,均一膜厚の成膜 を行わなければならない.そのためには,イオンビームの 分布が線形で表せる領域において基板を遊星運動させ, 成 膜を行う必要がある．線形であらわされるビーム領域を 得るためには, 成膜面積よりもはるかに大きい面積を持つ イオンビームが必要となる，Kaufman型IBS装置を使用し た成膜において, $1.5 \mathrm{ppm}$ 損失のミラー作製に成功していた が, Kaufman型のようにフィラメントを用いてイオンビー ムを作る場合, 良質且つ不純物混入の小さい大口径イオン ビームを得ることは困難である。したがって, 不純物混入 確率が小さく良質な大口径イオンビームを得やすいRF型 IBS装置での大口径超高品質薄膜の開発を行った。成膜当 初, グリッドからの不純物発生, ニュートラライザーから の高エネルギー電子の発生, Kaufman型IBSとのラジカルイ オン発生率の違いなどにより高品質な膜は作製できず6), ミラーの損失は100ppm程度であった。しかし,イオンガン のパワーや酸素流量, ニュートラライザーより発生する電 子のエネルギーを最適化することにより, Kaufman型IBS装

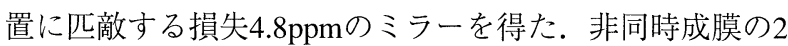
組のミラーにおいて, その損失值はほぼ同じであり, 定常 的にこの程度の損失のミラーが作製可能である。また， フィネスは約 $1 \times 10^{5}$ であり, 光子を $20 \mu \mathrm{s}$ という長い時間, 微 小空間に閉じ込めておくことが可能でありながら, 76\%以 上の共振器透過光を得ることが出来る。この事実は, レー ザーの周波数安定化, QED, FELなどの実験において非常に 重要な意味を持つ．Kaufman型とRF型IBS装置で作製した ミラーについての反射率面分布の測定を行った. Kaufman 型IBS装置で作製したミラーでは, 反射率の平均値99.9810 $\%$, 分散8ppm, RF型IBS装置で作製したミラーでは反射率の 平均值 $99.9915 \%$, 分散 $15 \mathrm{ppm}$ を得た。現状ではRF型IBS装 置で作製したミラーの方が若干大きな反射率面分布を 持っている．損失については, TAMA-300のプロトタイプ である $20 \mathrm{~m}$ 干渉計用に作製されたミラーについて, 小口径 ビームで損失面分布を測定するとともに, $20 \mathrm{~m}$ の FabryPérot共振器を組み, 大口径ビーム時の損失測定を行った. 損失面分布の平均值は, 測定領域 $7.5 \times 5 \mathrm{~mm}$ において $40 \mathrm{ppm}$ であった。また, 20mのFabry-Pérot干渉計における測定で の損失值は $28 \mathrm{ppm}$ となった。損失面分布の測定において, 例外的な大損失部分を除いた平均值は, $27 \mathrm{ppm}$ であった。 成膜における, 膜欠陥の発生率は低くTAMA-300用ミラー においても,この程度の損失のミラーを得ることは十分に 可能であると考えている.Fig.7に超低損失ミラーの開発 経緯を示す。超高品質ミラーの開発当初その損失は, 200ppm近くであったが, 1996年にはKaufman型IBS装置で $1.5 \mathrm{ppm}$ の損失ミラーの開発に成功し, ミラーの性能を2桁向 上させた。また, 1998年には, RF型IBS装置で4.8ppm損失の

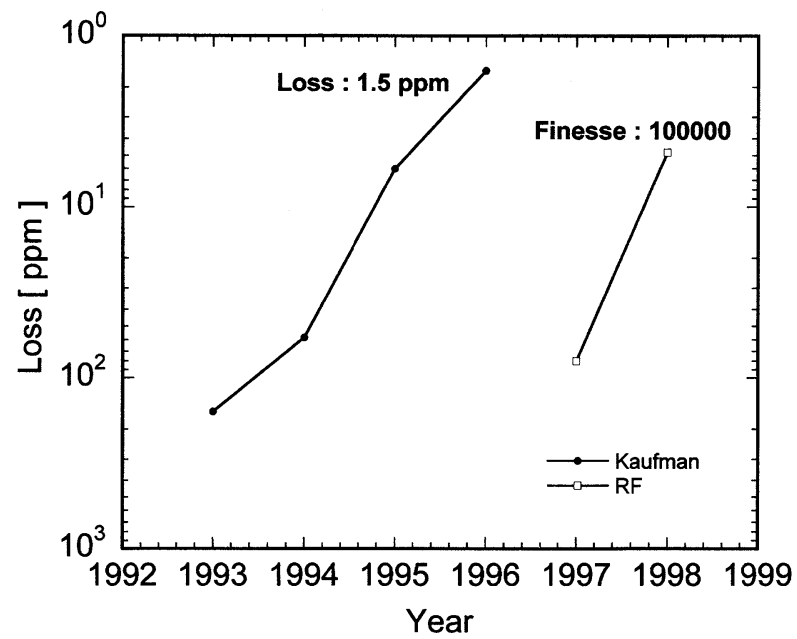

Fig.7 The history of developing ultra-high-quality mirrors. The loss of the mirror fabricated with the Kaufman IBS machine reached to $1.5 \mathrm{ppm}$ in 1996 . We obtained ultra-low-loss and high finesse cavity in 1998, The mirrors were fabricated with the RF-type IBS machine.

Table 2 Final specification of the TAMA-300 mirrors.

\begin{tabular}{cc}
\hline \hline Mirror diameter & $100 \mathrm{~mm}$ \\
Coating machine & $\mathrm{RF}^{-t y p e ~ I B S ~ m a c h i n e ~}$ \\
Materials of coating & $\mathrm{Ta}_{2} \mathrm{O}_{5}$ and $\mathrm{SiO}_{2}$ \\
Number of layers & 30 \\
Reflectance & $\geqq 99.99 \%$ \\
Surface distribution of reflectance & $\leqq 10 \mathrm{ppm}$ \\
\hline \hline
\end{tabular}

ミラーの開発に成功した。このミラーは超低損失であり ながら, そのフィネスは, ほぼ10万に達した。最後に, 重力 波干渉計用ミラーの最終仕様をTable 2に示す.

謝 辞

この研究の一部は文部省科学研究費補助金の援助を受 けて行われた。ここに記して謝意を表する。

\section{参考文献}

1) R. W. P. Drever, J. H. Hall, F. V. Kowalski, J. Hough, G. M. Ford, A. J. Munley, and H. Ward: Appl. Phys. B31 (1983) 97.

2) N. Uehara and K. Ueda: Appl. Phys. B61 (1995) 9.

3) N. Z. Anderson, J. C. Frisch, and C. S. Masser: Appl. Opt. 23 (1984) 1238 .

4) A. Ueda, N. Uehara, K. Uchisawa, K. Ueda, H. Sekiguchi, T. Mitake, K. Nakamura, N. Kitajima, and I. Kataoka: Opt. Rev. 5 (1996) 369.

5) A. Ueda and K. Ueda: 光学 27 (1998) 530.

6) 潟岡 泉, 伊藤 和彦, 関根 敬一, 江藤 和幸, 西田恵美子: 応用 物理 66 (1997) 1345 . 